\title{
RESISTANCE WHILE MANAGING ITS OWN INERTIAL POWER FIELD
}

\author{
N. Dimitrova* \\ Department of Foreign Languages and Information Technologies, National Sports Academy \\ "Vassil Levski", Sofia, Bulgaria
}

\begin{abstract}
The study of the managing methods represents particular interest in the biomechanics for the human body motor as well the opportunities for its improvement. (1) The basic problem related to the managing is to understand and to be aware of the task itself, the performance and the possibility for the reproduction. $(2,3)$ Therefore the aim of this study is to try to determine the quantity of the basic parameters of the balanced resistance and also during the examination in order to influence the managing method. There were examined 85 individuals (33 women and 52 men) taking part in the test. The test battery includes performing of the supporting human body tasks on a stable graphic platform. The projections of the Gravity Centre have been studied and the task for the individuals submitted to the test is to manage the Gravity Center having their full conscience. During the performance a quantity difference has been observed and therefore we could establish the conclusions related to the degree of consciousness regarding the managing methods.
\end{abstract}

Key words: managing, supporting human body task, balanced resistance.

\section{INTRODUCTION}

The improvement of the management of the human body motor has been always the basic moving factor during the human evolution. The managing principles are considered common for all kind of experiments regardless of the system for which they are applied. $(4,5)$ Therefore the study of the methods and the possibilities of its movement are extremely important for many scientific disciplines and as a general rule this great importance leads to the creation of another discipline - the cybernetics as a science for the management of complex dynamic systems and based on information procedures which are acting in themselves or among them and the environment as well. (6)

The Management theories study the human body motor as a complex system having many freedom levels depending on each other and therefore they allow the performance for

*Correspondence to: Nikolina Dimitrova,National Sports Academy, Sofia, Department for Foreign

Languages and Information Technologies, Studentski grad 1700 Sofia, Bulgaria, E-mail ninansa@abv.bg several tasks related to human body motor. (7) These tasks could be performed while including different elements from the whole system as well the management of all the elements accomplishing the task; all that is done till great extent unconsciously. This kind of the uncompleted managing process, the system itself with all its performings as well the important individual differences lead to significant difficulties having in mind the criteria related to management efficiency.

The basic problem during the study of the human body motor is the level of conscience of the human motor task and respectively the management level regarding the individuals performing the task itself And as we know already only when is the case of limited (impossibility of performing and performing as well for a longer period of time) human body tasks, then we could be sure concerning whole management of the elements in clouded in he execution for a determined body task. (8) In spite of the above-mentioned factors included in the management basic system, during the study itself we can draw conclusions for the conscience level and the 
management methods. One of these human body task is to keep the balance or the so called the balance resistance itself $(9,10)$.

Therefore the aim was to make a test in order to determine the quantity of the basic parameters of the balance resistance to influence the managing methods.

\section{METHODS}

There were examined 85 individuals (33 women and 52 men).

THE EXAMINED INDIVIDUALS THE FOLLOWING TASKS HAVING IN MIND THE CONDITIONN FOR MINIMUM DEVIATION FROM THE PROJECTION OF THE GRAVITY CENTER:

1. Inclination left- right.

2. Rotation in the hip.

3.Inclination left-right after feedback provided. 4.Inclination in the hip after feedback provided.

The above mentioned tasks were performed on stable graphic platform measuring the reactions of the support, location and

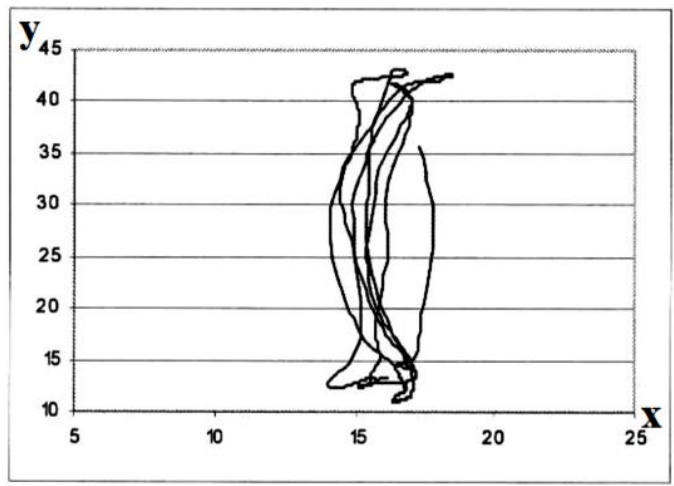

Figure la. Projection of the GC while

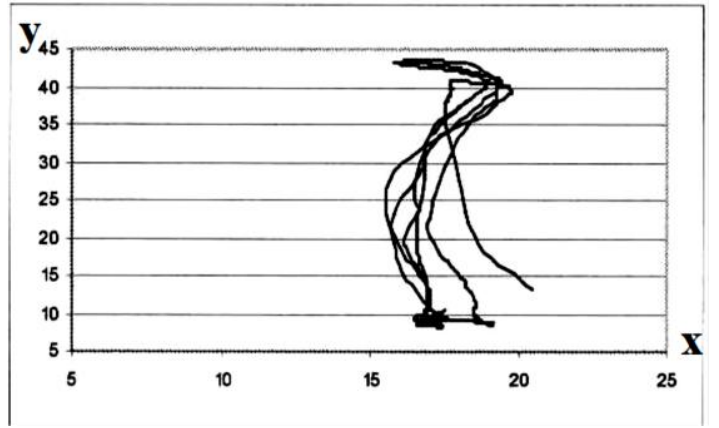

Figure 2a. Projection of the GC when Inclinations
DIMIROVA N.

projection of the Gravity Center as well the distribution of the pressure on the contact surface, For the purpose of the analysis were studied during 10 seconds the graphics outlined from the projection of the Gravity Center.

The primary work out of the data gave as the opportunity to construct some groups according to managing method of the balanced resistance.

\section{RESULTS AND ANALYSIS}

On Figures 1, 2 and 3 are presented the curves of the projection of the Gravity Center for the performance of the designed body human task and the individuals taking part in the test, they needn't use their conscience to monitor their activity task. On Figure 1 we can see the projection of the Gravity Center / $\mathrm{GC} /$ follows the directions of the movement itself as well the respective circle movement on Figure 1b, however on Figures 2 and 3 the movement is controlled when the direction changes.

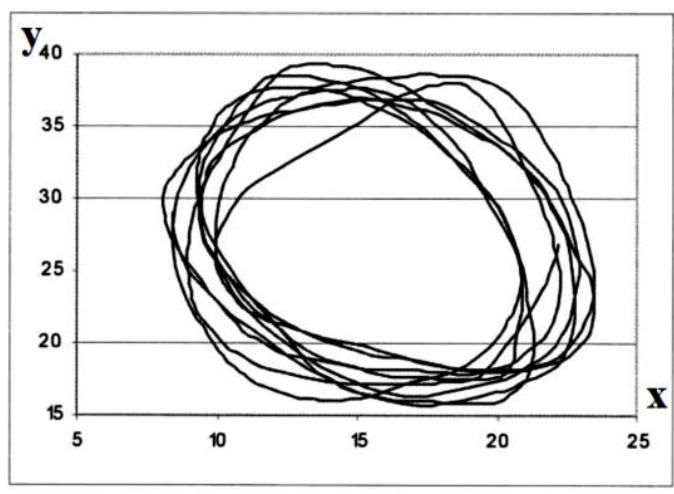

Figure 1b. Projection of GC when rotation left-right. Typical case for group 1

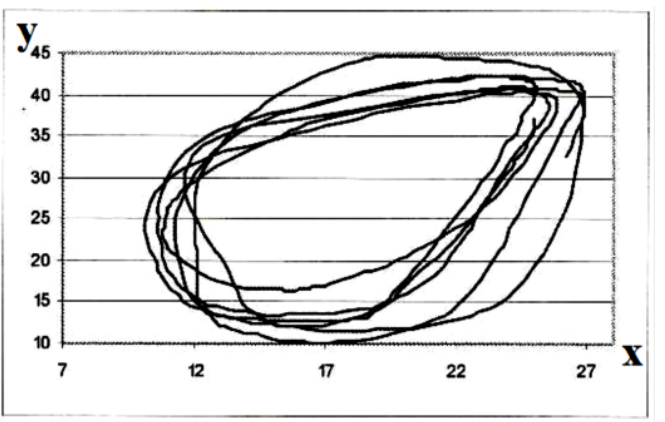

Figure 2b. Projections of GC when left-right Typical case for group 2 in the hip. 


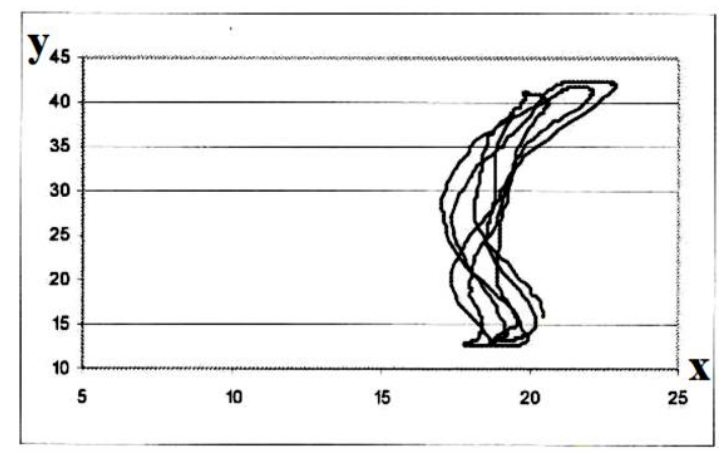

Figure 3a. For projectios of GC when inclinations

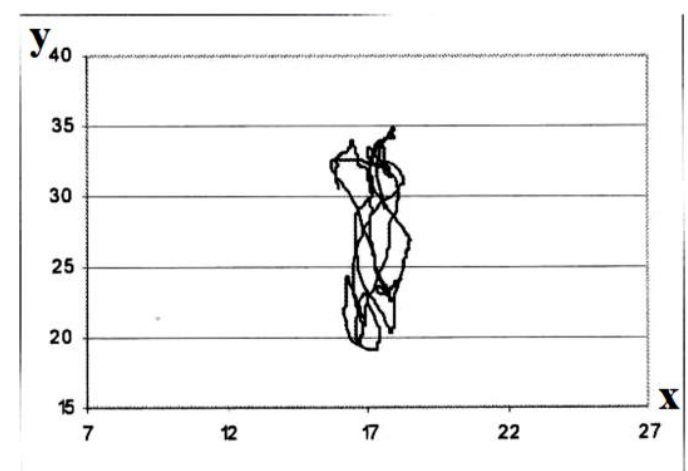

Figure 4a. Projection of GC when inclinations

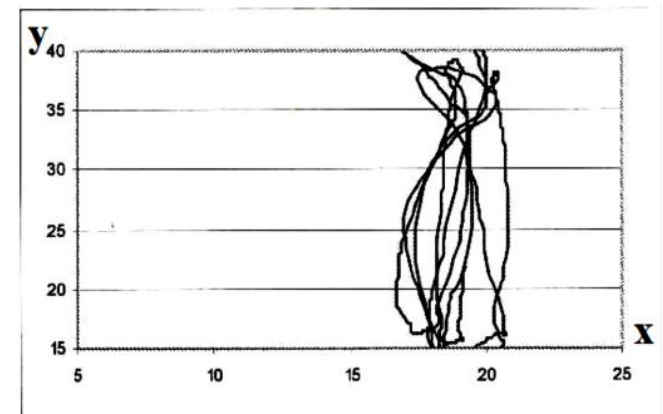

Figure 5a. Projection of Gr. C when inclination

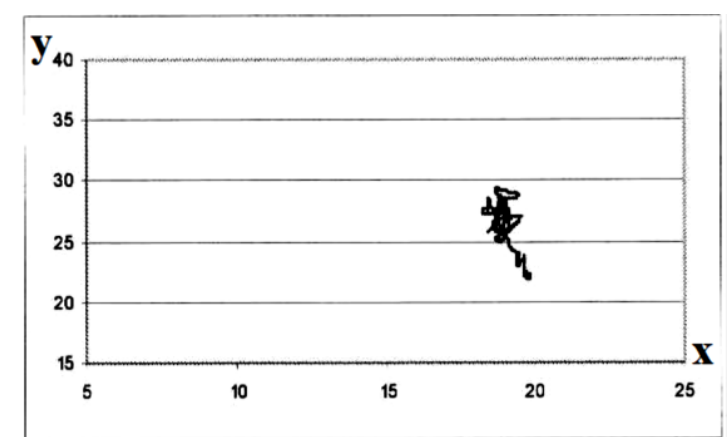

Figure 6a. Projection of GC when inclination.

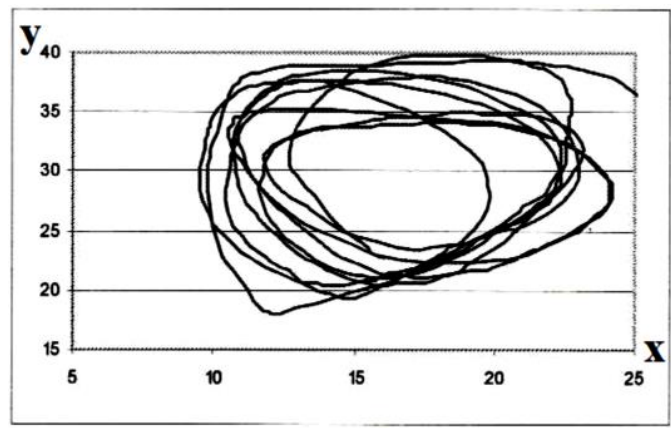

Figure 3b. Projections of GC when rotation leftright. Typical case group 3.in the hip.

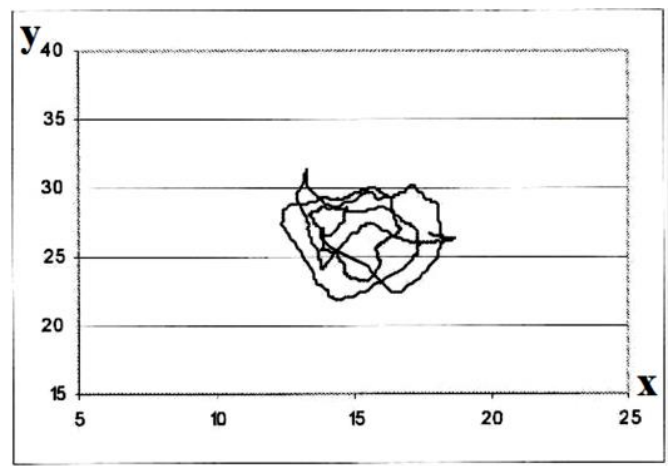

Figure 4b. Projection of Gr. C. with rotation leftright and minimum one in the hip with designed purpose with minimum deviation Typical case group 1. deviations Typical case group 1.

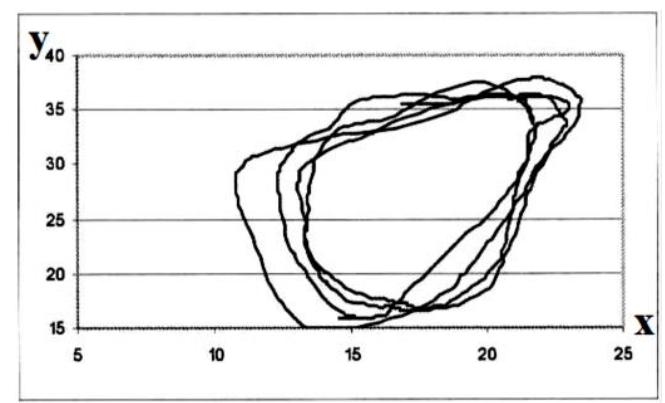

Figure 5b. Projection of Gr. C. with rotation leftright and minimum one in the hip with designed purpose with minimum deviation Typical case group 2. deviations Typical case group 2 .

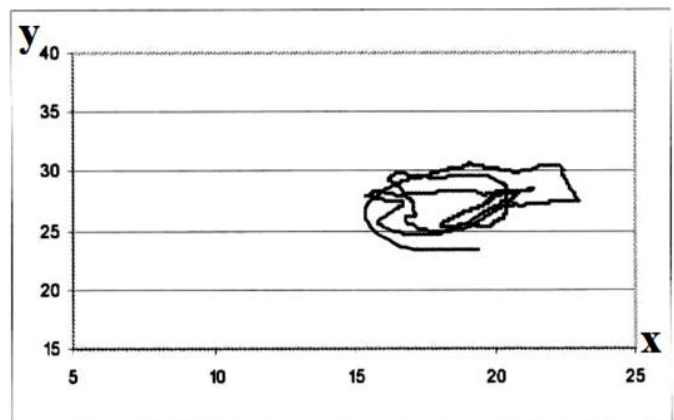

Figure 6b. Projection of GC when rotation left-right with designed purpose and minimum ones in the hip and designed purpose with minimum deviations. Typical case group 3 deviations. Typical case group 3. 
On Figures 4, 5 and 6 are presented the projections of the Gravity Center with the same human activity body tasks but this time the test for the individuals for conscience monitoring of the GC itself. We are able to see the quantity difference inspite of the fact we couldn't be sure of the level conscience of the GC and respectively the monitoring level itself. On Figure 5 it could be noticed how the monitoring test changes the direction of the deviations.

\section{CONCLUSIONS}

From the analysis of the results we could outline the following conclusions:

$>$ The following basic groups included in the monitoring principles could be observed: Compensation in the whole surface; The Gravity Center follows the external event; A compensation could be noticed into a privileged direction.

D The performing result of the human body task for precision /balance resistance/ is influenced till great extent from several subjective factors/mainly degree of concentration related to the task itself, conscience level etc./

$>$ For the quality improvement related to the future we should study the existence of the cumulative effect when tests are repeated with extra feedback delay.

\section{REFERENCES}

1. Winter D.A.; Biomechanics and motor control of movement Wiley and sons, N.Y., 1997
DIMIROVA N.

2. Chkhaidze, L. B.; Coordination of voluntary movement of a person from the position of general laws of control and controlled systems. Prince Problems kipernetiki, M., B.8, pp.309-336,1962 (In Russian)

3. Adrian, M. J., J. M. Cooper. Biomechanics of human movement. Madison, WI \&:Brown \& Benchmark, 1995.

4. Bernstein N.A.; On the construction of motion, M., 1947 (In Russian)

5. Chkhaidze, L. B.; On the management of human movements. Moscow, Physical Education and Sport, p. 136, 1970 (In Russian)

6. Kogan, A. B. Biomechanical Cybernetics. Higher school, M., 1977 (In Russian)

7. Ivanov Sv .; Methodology of biomechanical analyzes, Dissertation work, 1989 (In Bulgarian)

8. Frank, J., M. Earl. Coordination of posture and movement, Phys. Therapy, v.70, 1990.

9. Pendeva M .; Ivanov Sv .; Dimitrova N .; "Frequency stability characteristics"; Annual Scientific Conference 2223.05.1998g Sport, Society, Education. Volume 4, pp. 220-226; NSA Press, Sofia, 2001 (In Bulgarian)

10.Naydenova, K., K. Grozdanova, R. Penov., Study of the state of static equilibrium resistance in students from lower secondary stage of primary education. Sports and Science, (Sofia), LX, 2016, N 3, p.81-86. 